\title{
๑ GÊNERO, RAÇA E CÁRCERE: \\ O DIAGNÓSTICO DA MULHER NEGRA NA CRIMINALIDADE E OS DIREITOS DA PERSONALIDADE
}

\author{
GENDER, RACE AND PRISON: \\ THE DIAGNOSIS OF BLACK WOMAN IN CRIMINALITY AND THE RIGHTS OF \\ PERSONALITY
}

\begin{abstract}
(D) Leda Maria Messias da Silva Universidade Cesumar (UNICESUMAR) Pós-Doutora em Direito pela Universidade de Lisboa (Portugal) Professora do mestrado e doutorado da Unicesumar Maringá, PR. lemead@uol.com.br
\end{abstract}

\author{
Rosely Camilo Pereira Gomes \\ Universidade Cesumar (UNICESUMAR) \\ Mestra em Direitos da Personalidade pela UNICESUMAR \\ Maringá, PR. \\ rosely-gomes@hotmail.com
}

Resumo: O presente artigo propõe-se a refletir sobre a situação da mulher negra na sociedade brasileira e seu envolvimento com a criminalidade, a partir da explanação de aspectos históricos sobre o surgimento e evolução do racismo e suas consequências. Assim, tem como objetivo demonstrar que o racismo, sobretudo contra as mulheres negras, e as consequências que dele derivam, é uma prática que ainda está disseminada em nossa sociedade e que, neste caso em particular, conduz a mulher negra ao envolvimento maior com a criminalidade. A pesquisa se baseia nos estudos de Barroso (2012), Bonnici (2005), Chiavenato (1980), Prudente (1988), Dijk (2005), Szaniawski (2005), entre outros. O método utilizado foi o dedutivo, o qual a partir de pontos particulares, chega-se a conclusões gerais.

Palavras-chave: mulher negra; criminalidade; cárcere.

Abstract: This article aims to reflect on the situation of black women in Brazilian society and their involvement with crime, from the explanation of historical aspects about the emergence and evolution of racism and its consequences. Thus, it aims to demonstrate that racism, especially against black women, and the consequences that follow from it, is a practice that is still widespread in our society and that, in this particular case, leads black women to greater involvement with criminality. The research is based on the studies of Barroso (2012), Bonnici (2005), Chiavenato (1980), Prudente (1988), Dijk (2005), Szaniawski (2005), among others. The method used was the inductive one, which from particular points comes to general conclusions.

Keywords: black woman; crime; prison. 
SILVA, Leda Maria Messias da; GOMES, Rosely Camilo Pereira. Gênero, raça e cárcere: o diagnóstico da mulher negra na criminalidade e os direitos da personalidade

Para citar este artigo (ABNT NBR 6023:2018)

SILVA, Leda Maria Messias da; GOMES, Rosely Camilo Pereira. Gênero, raça e cárcere: o diagnóstico da mulher negra na criminalidade e os direitos da personalidade. Revista Thesis Juris - RTJ, São Paulo, v. 10, n. 2, p. 280-293, jul./dez. 2021. http://doi.org/10.5585/rtj.v10i2.18331.

\section{Introdução}

"Maria", ao fim de um dia de trabalho como empregada doméstica, se dirige a caminho de casa levando sobras de alimentos e gorjeta da patroa que serviria para comprar remédio para os dois filhos menores. Ela é mãe de três filhos. No interior do ônibus se encontra com o pai de um dos filhos e se alegra pelo fato de o homem se lembrar dela e por se interessar em saber sobre o filho com quem não convivia. $\mathrm{O}$ auge da narrativa se dá quando, apesar de ter sentado ao seu lado para conversar, o ex-marido repentinamente se levanta para assaltar os passageiros do ônibus. Maria, que tinha sido vista em sua companhia, é tomada como comparsa e é, por isso, assassinada, fato que a impossibilita de chegar em casa com as sobras de alimentos da patroa e com o recado do pai de seu filho.

O resumo acima trata-se do conto "Maria" retirado da obra "Olhos d'água" (2016) de Conceição Evaristo, uma das vozes mais importantes da literatura afro-brasileira que busca dar visibilidade sobretudo a mulheres negras. "Maria" é uma personagem representativa de todas as 'Marias' - mulheres, negras e de classe baixa - ou seja, triplamente discriminadas em uma sociedade marcada pelo preconceito racial, social e pautada num modelo patriarcal.

Os textos literários produzem um imaginário social, ao mesmo tempo que dele provêm, tornando-se um veículo prazeroso de conhecimento e compreensão do direito. Esta interação do direito com a literatura pode ser expressado como "diálogo das fontes". A fonte literária, por meio da ficção e suas personagens, retrata a realidade social e conduz a uma reflexão crítica do direito.

Assim, o tema em questão tem como objetivo analisar a situação da mulher negra na criminalidade, seus direitos da personalidade e suas consequências. Para tanto, primeiramente se realizará uma análise sobre a origem e perpetuação do racismo no Brasil, juntamente com a desigualdade de gênero que ainda é latente em nossa sociedade.

Após, far-se-á uma breve análise dos direitos da personalidade, tendo em vista que a história evidencia que estes direitos, inerentes à pessoa humana, foram/são negligenciados a estas cidadãs. 
SILVA, Leda Maria Messias da; GOMES, Rosely Camilo Pereira. Gênero, raça e cárcere: o diagnóstico da mulher negra na criminalidade e os direitos da personalidade

Na sequência, objetiva-se demonstrar como a relação entre gênero, raça e cárcere estão interligados formando um círculo vicioso que priva a mulher negra do pleno acesso aos direitos fundamentais, com destaque à liberdade, fato que acarreta um cotidiano precário, desigual, com restrição do mínimo para que se possa viver com dignidade.

Salienta-se que foram utilizadas pesquisas teóricas em livros, artigos, legislação e estatísticas em órgãos oficiais, além do método indutivo, o qual a partir de pontos particulares, chega-se a conclusões gerais.

\section{Gênero e os aspectos históricos do racismo no Brasil}

Assim como no conto de Conceição Evaristo, vê-se o local que a mulher negra de classe baixa ocupa na sociedade. Quanto ao gênero, não é necessário aprofundar-se a discussão, uma vez que é manifesto que o patriarcalismo ainda é estrutural em nosso país. Isso é facilmente provado, dados os números das pesquisas. Quanto à representatividade política apenas 10,5\% dos assentos da câmara dos deputados são ocupados por mulheres (IBGE, 2018). No que toca à representação no Poder Executivo, somente uma vez na história, uma mulher foi eleita Presidente da República. Quanto ao universo da advocacia, embora as pesquisas revelem que as mulheres são maioria, nunca uma mulher ocupou o cargo de presidente do Conselho Federal da Ordem dos Advogados do Brasil (OABSP, 2019).

Verifica-se, pois, o fenômeno da segregação hierárquica, ou seja, as mulheres estão subrepresentadas nos cargos de comando, tanto nos eletivos, conforme demonstrado, quanto nos gerenciais das empresas privadas. Nestas, apenas 39,1\% têm mulheres em posições de destaque (OABSP, 2019).

Quanto ao segundo fator discriminante, qual seja, a raça, principal foco deste estudo, torna-se necessário, neste momento, revisitar o passado para compreender o presente.

A história evidencia que a escravidão entre os povos existiu desde a antiguidade, tendo sua motivação em diversos fundamentos, sendo a guerra o seu fator principal. Assim, neste artigo almeja-se traçar linhas gerais sobre o início da escravidão e o racismo, já que este estudo não tem fôlego para esgotar a matéria. No entanto, torna-se necessário aqui escolher um ponto de partida na história sobre o tema, uma vez que o foco deste artigo assim requer.

Para isso, elegeu-se o marco histórico da descoberta da América, o qual é nominado de "zona de contato". Este é um espaço social em que "culturas diferentes se encontram, lutam, interagem, frequentemente através de relacionamentos altamente assimétricos de dominação e de subordinação" (PRATT, 1992, apud BONNICI. p. 57). 
SILVA, Leda Maria Messias da; GOMES, Rosely Camilo Pereira. Gênero, raça e cárcere: o diagnóstico da mulher negra na criminalidade e os direitos da personalidade

A Arte, como se sabe, é forma eficaz de conhecer a História, uma vez que as obras são parte e produto da sociedade, influenciada e influenciadora. Deste modo, a descoberta e a conquista da América pelos Espanhóis, retratada na pintura denominada América, de Jan vam der Straet, demonstra o encontro (zona de contato) do colonizador com o colonizado em que se pode perceber a diferença aplicada entre o eu e o outro. Ou seja, retrata a instalação do binarismo, local em que o significado se constrói a partir da diferença (centro/periferia; branco/preto; sagrado/profano), traduzindo, assim, a ideia de posição superior em que os europeus colonizadores se colocavam em relação ao colonizado, a hierarquização humana que culmina na discriminação, conforme será falado mais adiante.

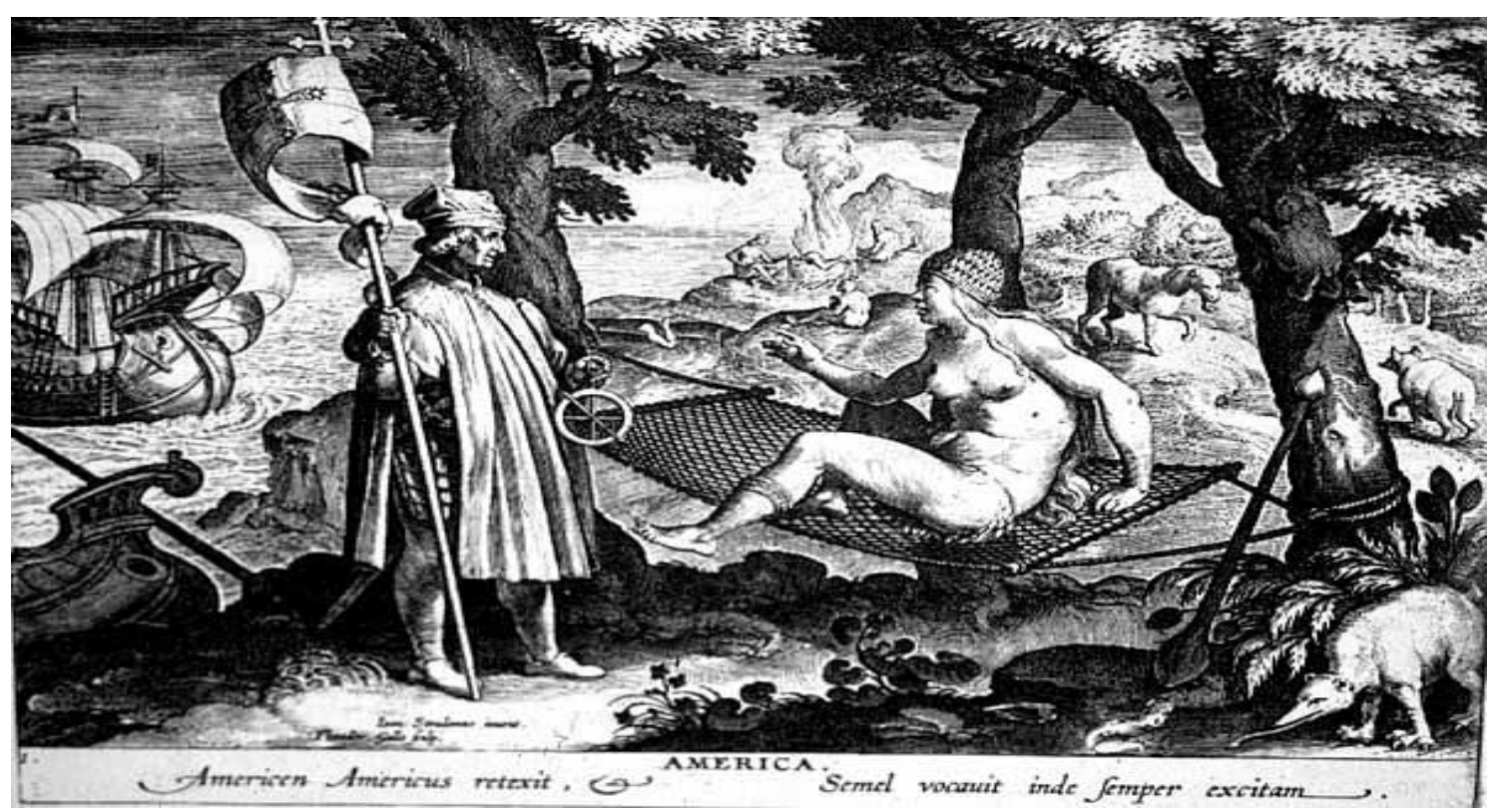

http://ccat.sas.upenn.edu/romance/spanish/219/07colonial/america.html

Nesta obra de arte pode-se perceber a posição imponente do colonizador, em pé, com as mãos cheias (astrolábio, bastão), o que retrata muito a oferecer, a ensinar. No outro lado da tela, a índia apresenta-se em posição deitada, com as mãos vazias (nada a oferecer) retratando o despertar com a chegada do colonizador.

Todorov (2010, p. 4), ao discorrer sobre a visão de Cristóvão Colombo e seus companheiros europeus sobre os índios, afirma que são "[...] tão estrangeiros que chego a hesitar em reconhecer que pertencemos a uma mesma espécie".

Ou seja, o "Outro" toma a si e a sua posição como padrão ao qual devem ser comparadas e medidas todas as outras coisas e pessoas, sem levar em conta a perspectiva do "outro". A denominação de "Outro" (grand-autre) e "outro" (petit-autre) é tomada dos estudos de Jacques Lacan (1901-1981). É o que a doutrina nomina de "outremização", ou seja: "é o processo pelo 
qual o discurso imperial fabrica o outro. O outro é o excluído que começa a existir pelo poder do discurso colonial. Constitui-se o Outro colonizador quando os outros colonizados são fabricados" (BONNICI, 2005, p. 44).

Em tais registros, Colombo alterna confissão de ignorância com supostas "certezas" e "[...] não se trata mais de procurar a verdade, e sim procurar confirmações para uma verdade conhecida de antemão (ou, como se diz, tomar desejos por realidade)" (TODOROV, 2010, p. 27).

Tal perspectiva é também adotada por Edward Said, em seu célebre livro "Orientalismo" (2007, p. 105): "[...] o que o orientalista faz é confirmar o Oriente aos olhos de seus leitores; ele não tenta, nem quer desestabilizar convicções já firmes".

Percebe-se, pois, que a partir deste marco histórico (descoberta da América), conforme mencionado por Julio José Chiavenato (1980, p. 168), "a escravidão vai apresentar indelevelmente formas racistas, utilizando-se especificamente uma raça (quando fracassa a exploração do índio) dada como inferior na escala humana e destinada 'naturalmente' ao trabalho escravo."

Assim, a distinção entre "civilizados" e "primitivos" foi um conceito adotado pelos europeus e seus descendentes espalhados pelo mundo e utilizados até os dias de hoje.

Também, as diferentes estruturas são desconsideradas. Algo que, conforme visto, se repete desde Colombo, que, sem entender que há outros sistemas (igualmente válidos) além do seu, observa que os índios têm "Uma generosidade que, às vezes, parece-lhe beirar a burrice: por que apreciam igualmente um pedaço de vidro e uma moeda?" (TODOROV, 2010, p. 54).

O mesmo raciocínio se aplica ao não branco e ao não europeu. Mesmo ainda que este seja estrangeiro ou o "bom selvagem" (Rousseau 1712-1778), a relação de inferioridade é sinal indelével na visão do conquistador. Uma visão maniqueísta que não mostra o desejo de realmente conhecer o outro, mas apenas de dominá-lo.

Tal pensamento reverbera até os dias de hoje e, da mesma forma que o conquistador quer apenas confirmar aquilo que considera como verdade, a "ciência" vem sendo usada com tal escopo no que se refere à classificação das raças.

A título ilustrativo, cita-se o naturalista francês Georges Cuvier (1769-1832) que postulou a existência de três raças: branca, amarela e negra, atestando, deste modo, a teoria da divisão de raças entre os seres humanos. Cita-se, ainda, o livro "O homem criminoso", do criminologista italiano Cesare Lombroso, em que afirmava que o delinquente tinha um biótipo supostamente inato. Outras teorias, como a frenologia, por exemplo, estudo da relação entre o formato do crânio e da capacidade intelectual do indivíduo, ganhou adeptos no século XIX 
(RANGEL, 2015). Assim, ficava assentido que características físicas estavam associadas a traços de caráter, inteligência etc.

Atualmente, outras categorias (caucasóide, mongolóide e negróide) foram estabelecidas, mas a ideologia de que uma é inferior à outra permanece, isso porque o preconceito foi validado por meio de um discurso (pseudo) científico, deixando pouco ou nenhum espaço para questionamento.

Embora haja pesquisas científicas contrárias a esta assertiva, lamentavelmente este pensamento reverbera até os dias de hoje, tendo contaminado, inclusive, quem tem o poderdever constitucional e legal de combater o racismo, sendo os negros os mais atingidos. Tal afirmação se confirma por meio de uma decisão proferida por uma juíza que, seguindo os passos de Lombroso, fundamentou sua sentença nos seguintes termos: "[...] Vale anotar que o réu não possui o estereótipo padrão de bandido, possui pele, olhos e cabelos claros, não estando sujeito a ser facilmente confundido" (FRANK, 2019).

No entanto, em sentido contrário a esta ideia não científica da diferença de raças, que sempre culmina na hierarquização humana, o antropólogo e professor estadunidense Robert Wald Sussman (2014), comprometido com a verdadeira ciência, defende o não agrupamento dos seres humanos em raças. Preocupado com esta vertente de classificação das raças, em sua obra The Myth of Race, demonstra o percurso da organização norte-americana Pioneer Fund, que objetiva provar associações entre genética e inteligência, caráter etc. Esta organização defende, ainda, a purificação da raça, ou seja, a eugenia.

Verifica-se, pois, da mesma forma que os colonizadores espanhóis queriam produzir provas para o que queriam acreditar, esta organização também tem o mesmo objetivo, qual seja: insistir em perpetuar a hierarquização humana, em convencer a humanidade que há inferioridade genética e, consequentemente, influenciar na legislação, nas políticas públicas, nos direitos civis, entre outros.

No Brasil, há pesquisas em sentido contrário à classificação humana em raças. Este estudo é liderado pela historiadora e antropóloga Lilia Moritz Schuwarcz. Em seu livro "O espetáculo das raças" (1993, p. 16), ela critica a divisão dos seres humanos em raças, para tanto, ela expõe o ponto de vista que vigorou no Brasil:

O país era descrito como uma nação por raças miscigenadas, porém em transição. Essas, passando por um processo acelerado de cruzamento, e depuradas mediante uma seleção natural (ou quiçá milagrosa), levariam a supor que o Brasil seria, algum dia, branco. 
A defesa, no Brasil, pela purificação da raça foi fortemente influenciada pelas ideias advindas dos Estados Unidos, bem como, da Europa, impactando na construção da estrutura social, que explicava as diferenças sociais, conforme defendida por Schuwarcz (1993, p. 23): "[...] o conceito raça, que além de sua definição biológica acabou recebendo uma interpretação sobretudo social."

Embora haja vozes relevantes da verdadeira ciência em sentido contrário à classificação humana em grupos raciais, é evidente no seio social que esta ideia se proliferou e ainda perdura até hoje, sendo utilizada de forma indiscriminada como verdade.

Observa-se, pois, que utilizando-se da classificação humana em grupos raciais, sobretudo em relação ao negro, dado como inferior na escala humana, como uma subespécie e destinado "naturalmente" ao trabalho, faz surgir o racismo.

Embora no Brasil a intolerância racial, após a abolição da escravidão, não tenha ocorrido de forma explícita por meio de legislação de segregação étnico-racial, como ocorreu nos Estados Unidos, o racismo se desenvolveu e ainda está arraigado em nossa sociedade de maneira camuflada. Ou seja, temos uma discriminação implícita, que muitas vezes aparece de forma sutil como, por exemplo, as que ocorrem por meio de brincadeiras, apelidos etc. A isso Dijk (2005) deu o nome de "racismo à brasileira". Este é, assim, muito mais difícil de combater, facilitando a perpetuação do racismo na forma praticada no Brasil, o que gera a negação dos direitos do negro, ferindo frontalmente sua dignidade humana e, o que fere a dignidade de um grupo, também fere a dignidade de todos.

Sob o ponto de vista legal, vivemos dois momentos históricos em relação a posição ocupada pelo negro na ordem jurídica brasileira, quais sejam: objeto de direito e sujeito de direito.

Até 1888 (ano da abolição da escravidão) o negro era considerado um objeto, ou seja, os escravos pertenciam à classe de bens móveis dos seus senhores, sendo que, com a morte destes, o escravo passava a integrar o acervo hereditário junto com os outros bens a serem partilhados entre os herdeiros. Os nascituros escravos eram denominados "fructos" ou "crias", tendo a Lei 1.237/1864, se referido a eles como "acessões naturais" (PRUDENTE, 1988).

Percebe-se, pois, que os negros eram objeto, verdadeira mercadoria, como relatado por Chiavenato (1980, p. 123): "[...] os negros eram vendidos por metro e por tonelada. Eram as 'peças das Índias', 'peças da África', as 'toneladas de negros' - representando os 'sopros de vida', os 'fôlegos vivos' [...]".

Viveu-se, neste momento histórico, o despojamento de qualquer direito de personalidade, já que este é dirigido à pessoa, qualidade que o escravo não ostentava. 
A partir de 1888 o negro adquire o status de sujeito de direitos e assume a condição jurídica de cidadão, ou seja, adquire personalidade.

\section{Direitos da personalidade}

A partir deste momento torna-se necessário tecer considerações sobre os direitos da personalidade, tendo em vista que os negros sofreram/sofrem violentas agressões a estes direitos inerentes à pessoa.

A personalidade em si não pode ser traduzida como um direito, mas sim, como um conjunto de atributos da pessoa humana, que tem início a partir do nascimento com vida, com proteção aos direitos do nascituro (art. $2^{\circ}, \mathrm{CC}$ ). Pode-se afirmar, assim, que ela é objeto do direito (SZANIAWSKI, 2005).

Goffredo Telles Júnior (1977, p. 315) define personalidade:

[...] a personalidade se resume no conjunto de caracteres próprios do indivíduo que é uma pessoa. É o conjunto dos elementos distintivos que permitem o reconhecimento desse indivíduo, primeiramente, como pessoa e, depois como uma determinada pessoa. A personalidade não é um direito. Mas é um objeto de direito. É um bem, no sentido jurídico. É o primeiro bem da pessoa, porque é o seu modo de ser. É seu primeiro bem, porque é o que primeiro pertence à pessoa; o bem que lhe pertence antes que outros bens lhe pertençam [...].

Elimar Szaniawski (2005, p. 70) esclarece que "[...] A proteção que se dá a esses bens primeiros do indivíduo, são denominados de direitos de personalidade [...]".

Assim, os direitos da personalidade, como traduz a sua denominação, decorrem da personalidade, e têm como valor máximo a proteção da pessoa humana. Pautado na dignidade da pessoa humana, são construções recentes, tendo vista que o Código Civil de 1916 não visava a proteção da personalidade, pois focava em proteger direitos de caráter patrimonial.

Ocorre que as transformações sociais vivenciadas no século XX, principalmente após as duas grandes Guerras Mundiais, não permitiam que a sociedade se pautasse em um sistema protetor unicamente da propriedade. Pode-se dizer que "tomou-se consciência da importância dos direitos da personalidade para o mundo jurídico" (SILVA; PEREIRA, 2013, p. 35). Assim, permeado pelos ideais da dignidade da pessoa humana, o novo Código Civil (Lei 10.406/2002) inaugurou um capítulo dedicado aos direitos da personalidade, vale dizer, o legislador positivou o que já estava disseminado na sociedade, referendando que o direito nasce do fato, da evolução social. Trata-se do Capítulo II, Título I - artigos 11 a 21, também chamados de direito civil constitucional, fruto da irradiação do conteúdo axiológico constitucional (BARROSO, 2012). 
SILVA, Leda Maria Messias da; GOMES, Rosely Camilo Pereira. Gênero, raça e cárcere: o diagnóstico da mulher negra na criminalidade e os direitos da personalidade

Conforme expõe a doutrina "Para o Direito Constitucional contemporâneo a dignidade da pessoa humana e os direitos fundamentais se vinculam naturalmente" (SILVA; VELTRINI, 2014). Por isso, pode-se afirmar que os direitos da personalidade são direitos fundamentais, constitucionalmente garantidos, em destaque no art. $5^{\circ}$ da $\mathrm{CF}$, o qual explicita o direito à vida, liberdade, igualdade, dentre outros. No entanto, nem todo direito fundamental se traduz em um direito da personalidade.

Ademais, importante mencionar que o rol de direitos da personalidade contido nos dispositivos legais são meramente exemplificativos, por força do que dispõe o $\S 2^{\circ}$ do art. $5^{\circ}$ da Constituição Federal. Assim, pode-se afirmar que o direito da personalidade tem uma proteção abrangente em relação a variadas formas de violação aos bens da personalidade. E, isso é possível, em razão da existência de uma cláusula geral e aberta de proteção da personalidade, qual seja: a dignidade da pessoa humana (SARLET; MARINONI; MITIDIERO, 2012).

Desta forma, conclui-se que os direitos da personalidade são dotados de essencialidade, imprescindíveis à pessoa humana, que, por consequência, irradia por todos os aspectos da sua vida: nome, integridade física e psicológica, saúde, imagem, honra, liberdade, reputação, direito ao próprio corpo, dentre outros. Ou seja, são direitos mínimos garantidores da dignidade da pessoa humana e de uma convivência livre e igualitária de qualquer pessoa, independentemente de sua origem, condição social, raça e cor.

\section{Relações entre gênero, raça e cárcere}

Como mencionado no tópico acima, a Constituição Federal de 1988, conhecida como constituição cidadã, inaugurou o Estado Democrático de Direito; elevou a dignidade da pessoa humana a um dos fundamentos da República (inc. III, art. $1^{\circ}$ ) e contemplou os direitos fundamentais da pessoa.

Ao se fazer uma retrospectiva observa-se que desde a elaboração da primeira constituição do Brasil (1824) houve uma grande evolução, sobretudo na busca da efetivação da igualdade entre homens e mulheres, momento em que o Estado elegeu como objetivos fundamentais promover o bem de todos, sem preconceitos de origem, raça, sexo, cor, idade, dentre outros $\left(\operatorname{art.} 3^{\circ}\right)$, além de ter tipificado como crime inafiançável e imprescritível a prática do racismo (inc. XLII, art. $5^{\circ}$ ).

Não obstante tal evolução na conquista de direitos e os ideais do novo modelo político se pautar na igualdade e cidadania, os fatos revelam a persistência de um comportamento sexista e racista, e que, as atrocidades cometidas no passado, sobretudo em relação ao negro, ainda se 
repetem no presente de forma camuflada ("racismo à brasileira"), despojando a maioria da população brasileira dos direitos da personalidade e, consequentemente, da sua dignidade.

Quanto às mulheres, a história evidencia que a luta pela igualdade de gênero aparece, desde seus primeiros passos no século XIX no Brasil, juntamente com a pauta da abolição da escravidão. Neste caso, vê-se a união das mulheres aos negros escravizados, uma vez que ambos, cada um a seu modo, ocupavam posição de subalternidade e opressão.

Como dito, a discriminação (gênero e raça), no Brasil, ocorre de forma implícita, que muitas vezes aparece de forma sutil, mas em outras, nem tanto. Tal assertiva pode ser ratificada diante das pesquisas que apontam o perfil da população prisional feminina. As estatísticas evidenciam um aumento alarmante da população prisional feminina no Brasil. Segundo dados do INFOPEN Mulheres (2018) entre 2000 a 2016 houve aumento de 656\%, enquanto a de homens, no mesmo período, foi de $293 \%$. Os índices revelam, ainda, que $62 \%$ desta população é composta por mulheres negras.

Com a apresentação destas estatísticas não se quer dizer que as mulheres aprisionadas não tenham cometido ilícitos passíveis da persecução penal, mas sim, que são vítimas de uma seletividade penal e da exclusão social que as conduziram da senzala para favela e desta para o cárcere. Conforme palavras de Edgar Morin (2007, p. 121): "[...] Compreender o assassino não significa tolerar o crime que ele comete [...] Compreender não é inocentar nem se abster de julgar e de agir, mas reconhecer que os autores de infâmias ou de faltas também são seres humanos". Pesquisas revelam que as mulheres negras são as mais afetadas pelo desemprego, sendo 50\% maior que a da população em geral, e sua renda salarial é 59\% inferior à dos homens brancos e 41,8\% inferior à das mulheres brancas (IPEA, 2018).

Em razão desta discriminação explícita revelada por meio de dados estatísticos, porém, camuflada pelo discurso social, a mulher negra não tem a mesma oportunidade de emprego frente à mulher branca, muitas vezes disfarçada no discurso de não corresponder ao "perfil" da empresa. Quando consegue alçar este degrau e se inserir no mercado de trabalho, ainda enfrenta outros fatores degradantes, quais sejam: diferença salarial; posições baixas na empresa, sem expectativas de ascensão, pois, também não teve a mesma oportunidade de acesso à educação formal para a sua qualificação. Todos esses fatores discriminantes a afastam do trabalho digno e formal e da oportunidade de redirecionamento de sua história de exclusão, fato que acaba conduzindo-a à criminalidade como a única forma de prover sua subsistência e da sua família.

Percebe-se, assim, que a mulher negra encontra-se triplamente discriminada na pirâmide social, sendo esta contemplada em seu topo pelo homem branco, seguida pela mulher branca, o homem negro, aparecendo a mulher negra somente após este, na base da pirâmide. 
Desta forma, se a mulher negra tem uma maior incidência de criminalidade, isto ocorre em razão da sua condição social, fruto do racismo e exclusão sofridos ao longo da sua trajetória histórica, conforme já exposto.

Assim, em consequência, a mulher negra lidera os índices do cárcere feminino. Quando o Estado exerce o seu poder-dever de dizer o direito ao caso concreto, e pune penalmente o infrator, ele não retira somente o seu direito à liberdade em sentido estrito. A restrição a este direito vem acompanhada de outras privações.

Este afastamento social da mulher negra, em razão da prisão, a afastará da possibilidade de acesso ao trabalho, e isto repercutirá em vários aspectos de sua vida. Sem trabalho que lhe proporcione uma renda, a família também sofrerá os efeitos do encarceramento, diante das privações materiais a que ficarão submetidos, pois não são raras as vezes em que a mulher é a única provedora do lar. Além disso, acaba gerando outro fator discriminante, a de ex-presidiária e, acompanhada de mais este estigma, elas são vistas como piores que os homens delinquentes, uma vez que esta posição contrasta com a construção da imagem feminina.

Ademais, importante salientar que a inserção da mulher no mundo da criminalidade geralmente ocorre em razão de seu envolvimento com o tráfico de drogas ilícitas, outra face do patriarcalismo, tendo em vista que na maioria das vezes ela é compelida a participar do crime por imposição do seu companheiro, para desenvolver funções na hierarquia do tráfico (também subalternas), ou pela falta de condições mínimas de sobrevivência digna.

Assim, vê-se a tripla discriminação da mulher negra fruto do patriarcalismo estrutural (gênero), associada à inferiorização étnica e de classe social, esta, resultante das duas anteriores. Ou seja, gênero/raça/classe estão intimamente relacionados e criam uma categoria de vulneráveis, em que são mais vítimas do que culpadas.

\section{Conclusões}

Conforme verificado, a discriminação racial é uma prática disseminada em nossa cultura, sobretudo em relação à população negra, que se revelou como um problema social maior, agravada pelas teorias da divisão humana em raças e as práticas eugenistas que, ao chegarem ao Brasil, encontraram um campo fértil para se desenvolverem.

Neste sentido, evidenciou-se que o Brasil seguiu os passos das ideias racistas desenvolvidas na Europa e nos Estados Unidos, locais em que se deram a construção da superioridade do homem branco, consequência de séculos de colonialismo europeu, que 
edificou o sistema de dominação do colonizador (Outro) com o colonizado (outro) fazendo emergir a ideia de hierarquização humana.

Em razão disso, os negros não foram escravizados e relegados a objeto de forma inconsciente, mas sim, de forma lúcida e racional com o intuito de anular a sua personalidade e subjugá-los à condição de coisa, com o aval das grandes instituições: igreja, estado, educação. Ademais, os afro-brasileiros sofreram, e os dados revelam que continuam sofrendo, ininterruptas agressões aos seus direitos de personalidade, mesmo que camufladas, como nos dias atuais.

Verificou-se, também, que o racismo moderno se apresenta de diversas formas, umas ocultas, outras, nem tanto. Isso se confirma por meio dos dados estatísticos que revelam o alto índice de aumento de encarceramento feminino, com destaque para a mulher negra, triplamente discriminada (gênero, raça e classe social) que em sua maioria vivem isoladas nas favelas, desempregadas ou subempregadas, sem moradia digna e alimentos para seus filhos, sendo conduzida, por esta realidade, ao mundo do crime, que ocorre não por opção, mas por imposição social, como foi demonstrado.

Diante de tantas barreiras sociais torna-se urgente uma indignação proporcional às discriminações raciais proliferadas em nossa cultura. Além do aspecto legal, é preciso combater o racismo em todas as suas formas, ainda que o modelo de racismo "sutil" disseminado em nosso meio seja o mais difícil de ser enfrentado, pois, para se combater a doença, é necessário reconhecer-se doente.

É urgente que as leis e as políticas públicas sejam elaboradas com este olhar e, sobretudo, que sejam efetivamente cumpridas. E, para que isto se concretize a mulher negra necessita de visibilidade e voz, algo alcançado por meio dos movimentos sociais. Daí sua extrema importância. Vê-se na história que grande parte das conquistas em benefício de "minorias" são advindas de pressão popular de movimentos sociais, organizados ou não, que impulsionam as políticas públicas em direção da garantia de direitos fundamentais (de personalidade) por eles reclamados. A exemplo disso, pode-se citar o voto feminino e o fato de o racismo ter sido tipificado como crime, entre outros.

Estes são movimentos de resistência que vão levar o indivíduo da condição de objeto para a de sujeito. Assim como Evaristo em "Maria", de "Olhos d'água", mostra resistência ao dar representatividade à mulher negra marginalizada como personagem principal, Chinua Achebe (1930-2013) escreve o primeiro romance que quebra a metanarrativa do discurso branco, "O Mundo se Despedaça” (1958). Nele há a contraposição da perspectiva europeia acerca da África exposta em “Coração da Escuridão” (1902), de Joseph Conrad (1857-1924), 
SILVA, Leda Maria Messias da; GOMES, Rosely Camilo Pereira. Gênero, raça e cárcere: o diagnóstico da mulher negra na criminalidade e os direitos da personalidade

que mostra o africano como selvagem e insociável. Ao contrário disso, em sua obra Achebe lança luz à uma sociedade organizada em diferentes aspectos (religioso, jurídico, civil etc.), porém ignorada e outremizada pelo invasor branco europeu.

Da mesma forma, a relação ocidente vs. oriente vem se repetindo ao longo da história: colonizador vs. colonizado, branco vs. negro, homem vs. mulher. Todos reproduzindo a oposição binária Outro vs. outro, que não fere apenas as duas partes individualmente envolvidas, mas todo o conjunto que cada uma delas representa.

\section{REFERÊNCIAS}

ACHEBE, Chinua. O mundo se despedaça. Trad. Vera Q. da Costa Silva. São Paulo: Companhia das Letras, 2009.

BARROSO, Luís Roberto. A constitucionalização do direito e suas repercussões no âmbito administrativo. In: ARAGÃO, Alexandre Santos de; MARQUES NETO, Floriano de Azevedo (coord.). Direito administrativo e seus novos paradigmas. Belo Horizonte: Fórum, 2012. p. 31-63. ISBN 978-85-7700-186-6.

BONNICI, Thomas. Conceitos-chave da teoria pós-colonial. Eduem. Coleção Fundamentum n. 12. 2005.

BRASIL. Ministério da Justiça e Segurança Pública. Levantamento nacional de informações penitenciárias - INFOPEN Mulheres, 2. ed. Brasília, DF, 2018. Disponível em: http://antigo.depen.gov.br/DEPEN/depen/sisdepen/infopenmulheres/infopenmulheres_arte_07-03-18.pdf. Acesso em: 05 out. 2019.

CHIAVENATO, Júlio José. O negro no Brasil. Da senzala à Guerra do Paraguai. São Paulo: Livraria brasiliense editora s.a., 1980.

CONRAD, Joseph. Heart of Darkness. Words worth Edition, London: 1999.

DIJK, Teun. A. Racismo e discurso na América Latina. São Paulo: Contexto, 2005.

EVARISTO, Conceição. Olhos D'agua. Rio de Janeiro: Pallas: Fundação Biblioteca Nacional, 2016.

FRANK, Gustavo. Juíza diz que réu não parece bandido por ter 'pele, olhos e cabelos claros'. Folha de São Paulo, 01 mar. 2019. Disponível em:

https://www1.folha.uol.com.br/cotidiano/2019/03/juiza-diz-que-reu-nao-parece-bandido-porter-pele-olhos-e-cabelos-claros.shtml. Acesso em: 24 mar. 2019.

IBGE. Estatística de Gênero: indicadores sociais das mulheres no Brasil. Atualizado 08 jun. 2018.

Disponívelem:https://biblioteca.ibge.gov.br/visualizacao/livros/liv101551_informativo.pdf. Acesso em 20 jun. 2019. 
IPEA (Instituto de Pesquisa Econômica Aplicada). Jovens e mulheres negras são mais afetados pelo desemprego. 30 out. 2018. Disponível em:

http://www.ipea.gov.br/portal/index.php?option=com_content $\&$ view=article $\& i d=34371 \&$ Ite mid=9. Acesso em: 22 out. 2019.

MORIN, Edgar. O método 6: ética. Trad. Juremir Machado da Silva. 3. ed. Porto Alegre: Sulina, 2007.

OABSP. Ordem dos Advogados do Brasil. Subseção São Paulo. Agora é que são elas. Jornal da Advocacia, Ano XLIV, n. 447, p. 10/11. mar. 2019. Disponível em https://www2.oabsp.org.br/jornal/Edicao447/page_1.html. Acesso em: 28 out. 2019.

PRUDENTE, Eunice. Aparecida de Jesus. O negro na ordem jurídica brasileira. Revista da Faculdade de Direito, Universidade de São Paulo, v. 83, p. 135-149, 1988. Disponível em: https://www.revistas.usp.br/rfdusp/article/view/67119. Acesso em: 17 dez. 2021.

RANGEL, Pollyanna Soares. Apenas uma questão de cor? As teorias raciais dos séculos XIX e XX. Revista Simbiótica, v. 2, n. 1, jun. 2015. Disponível em: https://periodicos.ufes.br/simbiotica/article/view/10324. Acesso em: 24 mar. 2019.

SAID, Edward. Orientalismo. Trad. Rosaura Eichenberg. Companhia das Letras, São Paulo: 2007.

SARLET, Ingo. W.; MARINONI, Luiz. G.; MITIDIERO, Daniel. Curso de direito constitucional. São Paulo: Editora Revista dos Tribunais, 2012.

SCHUWARCZ, Lilia Moritz. O Espetáculo das raças. São Paulo: Companhia das Letras, 1993.

SILVA, Leda M. Messias da; PEREIRA, Marice Taques. Docência (in) digna: o meio ambiente laboral do professor e as consequências em seus direitos da personalidade. São Paulo: LTR, 2013.

SILVA, Leda M. Messias da; VELTRINI, Maria C. Seara. A violação dos direitos da personalidade no pré-contrato, responsabilidade civil do empregador e a aplicabilidade do dano moral. I Congresso Internacional de Direitos da Personalidade. Disponível em: http://www.cesumar.br/prppge/pesquisa/mostras/pri_mestrado/pdf/03_GT4_Leda_Maria_Mes sias_Silva.pdf. Acesso em: 18 out. 2019.

SUSSMAN, Robert Wald. The Myth of Race. Harvard University Press, Cambridge: 2014.

SZANIAWSKI, Elimar. Direitos da personalidade e sua tutela. 2. ed. São Paulo:Revista dos Tribunais, 2005.

TELLES JUNIOR, Goffredo. Direito subjetivo. In: ENCICLOPÉDIA Saraiva do Direito. São Paulo, SP: Saraiva, 1977. v. 28.

TODOROV, Tzvetan. A Conquista da América: a questão do outro. Trad. Beatriz Perrone Moisés. 4. ed. São Paulo: WMF Martins Fontes, 2010. 